\title{
The Rules of Nomenclature for Micro-organisms
}

\author{
By G. C. AINSWORTH \\ London School of Hygiene and Tropical Medicine
}

The scientific names of organisms are the means by which one worker is able to relate his observations or opinions to those of others, and no one would benefit more than the microbiologist from an internationally acceptable and stable nomenclature. A large measure of agreement has already been reached on what constitutes an internationally acceptable name, but because appropriate and universally accepted names only reflect an agreed classification it will require much work by both systematists and experimental microbiologists before stability can be approached in many groups of micro-organisms. As a first step towards the goal microbiologists are urged only to use names which conform to international agreements because such usage makes for precision and at least does not hinder developments in classification. The purpose of this article is to advocate care in the use of names and to draw the attention of those who may wish to propose new taxonomic groupings or to change old names to certain requirements of the International Rules of Nomenclature. Also, systematists frequently feel obliged to make changes in the names of the groups of organisms which they study; changes which may at times seem arbitrary and unnecessary. A knowledge of the International Rules often enables the reasons for such changes to be more fully appreciated and sometimes allows a distinction to be made between name changes which are obligatory on all and those which need not be accepted at once, if ever, when they would disturb some long-established usage.

\section{The International Rules}

The names of animals are governed by the International Rules of Zoological Nomenclature, those of plants by the International Rules of Botanical Nomenclature. In 1930 the International Society for Microbiology at its first International Congress 'recognized that insofar as they may be applicable the nomenclatural codes agreed upon by the International Congresses of Botany and Zoology should be followed in the naming of microorganisms'. Fungi have been traditionally associated with plants, and mycologists accept the botanical code which includes several special clauses for their convenience. In 1930 the International Society for Microbiology also decided, in view of 'the peculiarly independent course of development' of bacteriology, that bacteriological nomenclature merited special treatment, and to that end set up an International Committee on Bacterial Nomenclature; later in the same year the two permanent secretaries of that committee being accepted by the Fourth International Botanical Congress as its Special Committee for Bacteria to make recommendations regarding bacterial nomenclature. In 1939 the International Committee on Bacterial Nomenclature was instructed to prepare a 'Bacteriological Code', and the publication of the code, when developed, was 
authorized by Congress on the understanding that it should be regarded as wholly tentative but in the hope that it would be widely tested. The war intervened, and it was not until the Fourth International Microbiological Congress in 1947 that a proposed code was approved. This tentative Code, which emphasizes the interdependence of bacterial and botanical nomenclature, is essentially an abbreviation and rearrangement of the Botanical Rules for bacteriologists, and in what follows any provisions of the Rules of Botanical Nomenclature applicable to bacteria have been tentatively accepted by bacteriologists.

\section{Similarities between the International Rules of Botanical and Zoological Nomenclature}

The zoological and botanical codes developed independently and each formally recognizes its independence: 'the name of an animal is not to be rejected simply because it is the name of a plant' (Zoological Rules, Article 1); 'the name of a plant is not rejected simply because it is the name of an animal' (Botanical Rules, Article 6). (Microbiologists, however, do not permit the use of duplicate generic names in the group Protista and deprecate the use of a specific name both in the Protista and in a plant or animal group; $J$. Bact. 33, 447,1937 .) In spite of this independence the two codes have much in common. Both accept Latin binomial names for species, state or imply that every species has but one valid name in any genus in which it may be classified, judge the validity of names by the 'law of priority', and determine the application of names of species, genera and other taxonomic groups by means of 'types'.

\section{Differences between the Rules of Botanical and Zoological Nomenclature}

The Botanical Rules, which attempt to prescribe procedure for any eventuality, consist of 74. Articles and 50 numbered Recommendations. The first 19 Articles deal with general principles, the remainder are the 'Rules'. The Recommendations supplement and amplify the Rules, and many botanists appear to consider certain of the Recommendations to be as binding as Rules. The Zoological Rules are more concise and comprise 36 Articles together with recommendations for the formation of new names and the choice of types. There have been few changes in the Zoological Rules since they were first instituted in 1901, but the International Zoological Congress held in Boston in 1901 empowered the International Commission on Zoological Nomenclature, the body which prepared the Rules, to render 'Opinions' on questions of their interpretation. So far nearly 200 Opinions have been given, and these are in effect an official supplement to the latest, 1913, version of the Rules. A Judicial Commission, similar to the International Commission of the Zoologists, is proposed for the new Bacteriological Code.

The debt which biologists owe to Linneus for introducing binomial nomenclature and a tribute to his outstanding ability as a taxonomist are acknowledged by both codes in the starting-points selected for international nomenclature. The tenth edition of Linné's Systema Naturae, 1758, is the single starting-point for zoological nomenclature. Botanists accept the first edition 
of his Species Plantarum, 1753, as the starting-point for the nomenclature of flowering plants and some other groups including Lichenes and Mycetozoa, and it has been agreed that this shall also be the starting-point for bacterial nomenclature. For certain groups which were inadequately treated by Linneus, botanists have selected a number of later starting-points. The nomenclature of Fungi, for example, begins at 1801 (Persoon, Synopsis methodica fungorum) for Uredinales, Ustilaginales, and Gasteromycetes and at 1821-32 (Fries, Systema mycologicum) for other fungi.

Both botanists and zoologists at times find that the strict application of the law of priority would, by disturbing long-established usage, make for greater confusion than order and each code has its own method for providing alleviation in such cases. An International Botanical Congress may 'conserve' a later generic name against an earlier one and the International Commission on Zoological Nomenclature may 'suspend the Rules in any given case, where in its judgement the strict application of the Rules will clearly result in greater confusion than uniformity', and a Judicial Commission will have the power to proscribe names under the Bacteriological Code. Under no circumstances is it at present possible to uphold a later specific epithet against an earlier one which does not infringe the Rules.

In addition to the above differences there is a number of minor and more technical, although not unimportant, differences between the two sets of Rules, and attention will later be drawn to certain of them which reflect differences in current botanical and zoological taxonomic practices.

\section{New species}

An author wishing to propose a new species has first to satisfy himself that it is not one of the perhaps thousands of allied species already proposed and then to describe its characteristics so that they are recognizable to others. This is not the place to discuss the taxonomic question as to what constitutes a good species in any particular group, but to indicate the requirements of the International Rules if a new name is to prove acceptable.

The name must be in Latin and be in binomial form. The generic name should be spelt with a capital initial letter and that of the specific epithet should have no capital. It has never been obligatory to use capitals for specific epithets. Under the Zoological Code there is a Rule and under the Botanical Code a Recommendation that certain classes of specific epithets may be spelt with capital letters, and this practice has in the past been more widely followed by botanists than by zoologists.

Botanists are recommended 'not to make names long and difficult to pronounce', and both sets of Rules offer advice on what constitutes good taste in the selection and spelling of names. The name and the accompanying description must be published (for the conditions of effective publication see Botanical Rules, Art. 36), and under the Botanical Rules 'after 1 January 1935, names of new groups of recent plants, the Bacteria excepted, are considered as validly published only when accompanied by a Latin diagnosis' (Art. 38). The Zoological Rules do not insist on a Latin diagnosis, but the 
Appendix to the Rules states that 'it is very desirable that the proposition of every new systematic group should be accompanied by a diagnosis, both individual and differential, of the said group in English, French, German, Italian, or Latin'. The same Appendix also advocates the use of the metric system of weights and measures in all descriptions and the expression of the enlargement or reduction of any illustrations in figures rather than by the system of lenses used.

The applications of the names of all taxonomic groups are determined by 'types', i.e. a family is based on a type genus, a genus on a type species, and a species or group of subspecific rank on a type specimen. Authors must always designate clearly the type on which their new group is based. When proposing a new species a zoologist is recommended to designate and label one specimen as the type, any other specimens examined by the author at the same time being paratypes. The types of species of fungi and bacteria may be descriptions with or without drawings or microscopical preparations. For bacterial species the type specimens are frequently cultures (when subcultures should be deposited in the principal culture collections of the world) and for microfungi they are commonly herbarium specimens. When a dried specimen, the type is frequently a 'collection' rather than an individual and it is probable that all the different parts of a single collection when deposited in several herbaria should be considered of equal status. If the type of a fungus is a culture, well-grown and typical cultures should whenever possible be dried as herbarium specimens, for in such form they are likely to be as much, or greater, use to future systematists as a living culture after a lengthy sojourn in a culture collection.

The account of a new species should always include the date of collection or isolation, the place of origin, and the host or substratum, if any, of the type material, and the location of the type specimen.

\section{Name changes}

'A generic or specific name, once published, cannot be rejected, even by its author, because of inappropriateness' (Zoological Rules, Art. 32). 'A name or epithet must not be rejected, changed or modified, merely because it is badly chosen, or disagreeable, or because another is preferable or better known' (Botanical Rules, Art. 59). Once a name has been validly published it cannot be eliminated. Even if reduced to synonymy it remains permanently as a name for the potential consideration of later workers. The Rules only permit the correction of a typographic error or a clearly unintentional orthographic error in the original spelling.

Names of species may, however, be changed for a number of reasons. The name may not be the earliest one, it may be a later homonym (i.e. the same name may have been applied previously to a different type), or, most commonly, it may need to be changed to accord with an author's views on classification. Under the Botanical Rules a change might also be necessitated because of tautonomy (i.e. because the specific epithet is an exact repetition of the generic name), but the Zoological Rules allow the use of tautonyms. If the 
new Bacteriological Code's acceptance of the botanical ruling is upheld such names as Fusiformis fusiformis Topley \& Wilson will become illegitimate.

The valid names for fungi which have perfect and imperfect spore forms are the earliest names given to the perfect states; names given to other states having only a temporary value (Botanical Rules, Art. 57). The discovery of the ascospore- or basidiospore-producing state of a fungus of which the conidial state only is known involves, therefore, a change in the name of the latter according to the strict interpretation of the Rules, although when the perfect state is rarely encountered it is convenient and customary to continue to use the imperfect name.

Both Codes require the authors' names, usually abbreviated, to be added to all formal citations of the names of the taxonomic groups which they have proposed. Changes in the generic names of species involve changes in the authority for the name. Under the Botanical Rules, when a species is transferred from one genus to another the name of the author of the original species is enclosed in brackets and followed by the name of the author making the change. Under the Zoological Rules the first author's name is enclosed in brackets but the second author's name is omitted. Similarly, double citation is required for changes in rank of botanical names. For example, Psalliota (Fr.) Quél. indicates that Psalliota was proposed as the name of a subgenus by Fries and first used as a generic name by Quélet. Zoologists would not consider such a change to be a change in rank, for they treat genera and subgenera as equivalent. Neither do they distinguish a difference in rank from the nomenclatural point of view between subspecies and species. This difference reflects the greater stability of botanical genera and accounts for another contrast between the two disciplines. In botany the name of a species is the complete binomial, e.g. Psalliota campestris, which comprises the generic name Psalliota and the 'specific epithet' campestris. In zoology the stress is on the specific epithet, which is known as the 'trivial name' of the species, the combination of a trivial name with an appropriate generic name constituting the 'designation' of the species. When considering questions of priority among specific homonyms in zoology it is the one with the earliest trivial which is accepted, while in botany it is the earliest combination (binomial) which must be maintained, even though it contains a later specific epithet than the rejected name.

\section{Synonyms}

Synonyms are different names applied to one taxonomic group, but current practice restricts the application of the term to rejected names. Since the introduction of the type method there are two distinct classes of specific synonyms, those which are synonyms by definition and those which are matters of opinion. Bacterium coli (Mig.) Lehm. \& Neum. and Escherichia coli (Mig.) Castel. \& Chalm. are synonyms of the first kind. Both names are based on the same type and must therefore be synonymous. Both names are equally valid, and which is adopted depends on whether the user considers that the species should be classified in the genus Bacterium as proposed by Lehmann \& Neumann or in the genus Escherichia of Castellani \& Chalmers. 
Bacillus vesiculi formans Henrici is listed in Bergey's Manual as a synonym of Escherichia coli, but this synonymy is a matter of opinion and not of definition. A second type is involved, and anyone is always at liberty to believe that the judgement of the authors of Bergey's Manual is at fault and that Bacillus vesiculi formans is the name of a distinct species. It is an aid to clear thinking if these two classes of synonyms are distinguished when citing synonymies, and this may be conveniently done by adding the name of the author whose judgement is accepted as the authority for a synonym of the second class, e.g. Escherichia coli (Mig.) Castel. \& Chalm., syn. Bacillus vesiculi formans fide Bergey et al.

\section{LITERATURE}

The current official version of the International Rules of Zoological Nomenclature, that agreed on by the International Zoological Congress of 1913, is out of print. The Rules have, however, been reprinted in C. M. Wenyon, Protozoology (1926) 2, 1936 (London) and in Proc. biol. Soc. Wash. (1926) 39, 75 (together with summaries of the first 90 Opinions), and in the useful book by E. T. Schenk \& J. H. Masters (1936), Procedure in Taxonomy (U.S.A. and Oxford Univ. Press, London). The 194 'Opinions and Declarations rendered by the International Commission on Zoological Nomenclature' have recently been published or are being republished in three volumes by the Commission (London), and in 1943 the same Commission instituted The Bulletin of Zoological Nomenclature in which proposals submitted to the Commission for deliberation and decision are printed. In the first issue of that Bulletin (Vol. 1, p. iv) there is an interesting article by $\mathbf{F}$. Hemming on the functions and powers of the International Commission.

The official French, English and German versions of the International Rules of Botanical Nomenclature were issued in 1935 (Gustav Fischer, Jena). The Rules have been reprinted (without the Appendices) in C. W. Dodge, Medical Mycology, pp. 76-96 (U.S.A., 1935; London, 1936) and (abbreviated) in Bergey's Manual of Determinative Bacteriology, 1939, 5th ed. They have also been reprinted and annotated for mycologists in G. R. Bisby, An Introduction to the Taxonomy and Nomenclature of Fungi, 1945 (Imperial Mycological Institute, Kew), a book which gives much useful information on procedure.

The Proposed Bacteriological Code of Nomenclature, edited by R. E. Buchanan and R. St John-Brooks, 1947 (Iowa State College Press), will be published in the Proceedings of the Fourth International Congress for Microbiology. It gives, in addition to the proposed rules, a historical account of their development and the opinions issued by the International Committee on Bacteriological Nomenclature and ratified by Congress during the period 1930-9.

'A discussion on the differences in observance between zoological and botanical nomenclature', Proc. Linn. Soc. Lond. (1944) 156, 126 and 'Discussion on mycological nomenclature', Trans. Brit. mycol. Soc. (1942) 25, 428, provide clear expositions of many points of detail. 